\title{
The contribution of epididymosomes to the sperm small RNA profile
}

\author{
Natalie A Trigg ${ }^{1,2}$, Andrew L Eamens ${ }^{1,2}$ and Brett Nixon ${ }^{1,2}$ \\ ${ }^{1}$ Priority Research Centre for Reproductive Science, School of Environmental and Life Sciences, The University of \\ Newcastle, Callaghan, New South Wales, Australia and ${ }^{2}$ Hunter Medical Research Institute, New Lambton Heights, \\ New South Wales, Australia
}

Correspondence should be addressed to B Nixon; Email: Brett.Nixon@newcastle.edu.au

\begin{abstract}
It is now well established that mature spermatozoa harbour a rich and diverse profile of small non-protein-coding regulatory RNAs (sRNAs). There is also growing appreciation that this sRNA profile displays considerable plasticity, being altered in response to paternal exposure to a variety of environmental stressors. Coupled with evidence that upon delivery to the oocyte at the moment of fertilisation, sperm-borne sRNAs are able to influence both early embryonic development and the subsequent health of the offspring, there is now interest in both the timing and degree of change in the composition of the sRNA cargo of sperm. Models in which such epigenetic changes are linked to the spermatogenic cycle are seemingly incompatible with the lack of overt phenotypic changes in the spermatozoa of affected males. Rather, there is mounting consensus that such changes are imposed on sperm during their transit and storage within the epididymis, a protracted developmental window that takes place over several weeks. Notably, since spermatozoa are rendered transcriptionally and translationally silent during their development in the testes, it is most likely that the epididymis-documented alterations to the sperm sRNA profile are driven extrinsically, with a leading candidate being epididymosomes: small membrane enclosed extracellular vesicles that encapsulate a complex macromolecular cargo of proteins and RNAs, including the sRNAs. Here, we review the role of epididymosome-sperm communication in contributing to the establishment of the sperm sRNA profile during their epididymal transit.

Reproduction (2019) 157 R209-R223
\end{abstract}

\section{Introduction}

The volume of studies reporting the inheritance of non-genome-derived information have increased over the past decade. This so-called epigenetic mode of inheritance challenges long held paradigms of classic Mendelian genetics by offering a rational mechanism for the transmission of environmental information to the offspring, which can conceivably lead to novel phenotypic outcomes. Mounting evidence for the existence of such alternate routes of inheritance includes examples from epidemiological analysis of humans and studies performed in model species ranging from worms to mammals (Kaati et al. 2007, Dunn \& Bale 2009, Lim \& Brunet 2013). Collectively, these studies provide an important precedence for the potential transmission of paternal traits acquired by environmental conditions to the offspring, suggesting the existence of additional 'information carriers' beyond that of an individual's genome. Among the information carriers potentially responsible for relaying non-genetic information between generations, considerable attention has focused on small non-protein-coding regulatory RNAs (sRNAs). Accordingly, mature spermatozoa harbour a rich and diverse sRNA profile, the foundations of which are established during the testicular phases of their development. Notably, however, recent evidence has shown that the sperm sRNA profile displays considerable plasticity, being substantially remodelled as the cells traverse the epididymis, an integral part of the extra-testicular male reproductive tract (Nixon et al.2015). Importantly, alteration of the sperm sRNA profile during epididymal transit has recently been shown to be essential for the production of functionally mature spermatozoa capable of supporting not only fertilisation, but also normal embryonic development (Conine et al. 2018). Moreover, the sRNA profile of sperm has also been demonstrated to be altered in response to a male's exposure to a number of environmental insults, with such alterations having been linked with significant post-fertilisation consequences, commonly converging on the transmission of altered behavioural and metabolic phenotypes to the offspring (Fullston et al. 2013, Rodgers et al. 2013, Short et al. 2016). The demonstration that such phenotypic changes can be recapitulated via the direct microinjection of sRNAs harvested from the sperm of insult-exposed males into otherwise 'normal' fertilised oocytes, effectively 
eliminates the contribution of germ-line-independent paternal factors, and further, implicates sRNAs as the causative agents (Gapp et al. 2014, Grandjean et al. 2015, Rodgers et al. 2015, Chen et al. 2016a). Nevertheless, while the list of environmental insults that influence the composition of the sRNA cargo of sperm continues to grow, the mechanism(s) responsible for mediating these changes to the sperm epigenetic landscape remains uncertain. Among the plausible scenarios, there is mounting consensus that such changes are imposed on sperm during their transit and storage within the epididymis. Notably, since spermatozoa are rendered transcriptionally and translationally silent before departing the testes (Kierszenbaum \& Tres 1975, Steger 1999), it is most likely that any alterations to the sperm sRNA profile in the epididymis are driven extrinsically, with a leading candidate being epididymosomes: small membrane enclosed extracellular vesicles that encapsulate a complex macromolecular cargo of RNA and protein. Indeed, there is recent evidence that chronic exposure of a male to insults such as alcohol elicits a change in their epididymosome sRNA cargo, a change that closely parallels the altered sRNA profile of exposed spermatozoa (Rompala et al. 2018). Given the hypothesized contribution of the sperm sRNA profile to the offspring, important emphasis should be placed on documenting the contribution of epididymosomemediated communication with the sperm as these cells transit the epididymis. Hence, we discuss here the role of epididymosomes in modulating the sperm sRNA profile during epididymal transit, paying particular attention to their contribution to the sRNA profile of sperm, a profile that is altered by paternal exposure to stress. Further, we also discuss the relevance of an altered sperm sRNA profile on the subsequent development of the embryo and the health of offspring.

\section{The action of small RNA species documented in spermatozoa}

It is becoming increasingly accepted that spermatozoa are more than mere vectors for conveying the paternal haploid genome to the oocyte. Indeed, beyond the paternal genome, spermatozoa harbour non-genetic information that can be propagated to the ensuing embryo. This epigenetic information includes a diverse RNA population (Chen et al. 2016b), and from this global RNA pool, sRNAs command considerable attention.

In spermatozoa harvested from the proximal caput segment of the epididymis, miRNAs are the mostabundant sRNA species (Hutcheon et al. 2017), accounting for approximately half of the global sRNA population. miRNA production begins with the transcription and folding of the primary-miRNA (pri-miRNA) transcript (Ambros et al. 2003). Next, the pri-miRNA is processed to yield a mature miRNA duplex via the action of two
RNase III-like endonucleases, DROSHA and DICER, and their partnering double-stranded RNA (dsRNA)binding (DRB) proteins, DGCR8 (DiGeorge syndrome critical region 8) and TRBP (transactivation-responsive RNA-binding protein) (Fig. 1A) (Lee et al. 2003, Haase et al. 2005, Ha \& Kim 2014). The miRNA/miRNA* duplex is subsequently loaded into the endonuclease, ARGONAUTE 2 (AGO2). While either strand of the miRNA/miRNA* duplex has the potential to act as a functional sRNA, only one strand is retained by $\mathrm{AGO} 2$ to form an activated miRNA-induced silencing complex, miRISC (Hu et al. 2009, O'Brien et al. 2018). miRNAs direct miRISC to regulate target gene expression by binding to lowly complementary target sequences, and in mammals, miRNA target sequences are almost exclusively harboured in the $3^{\prime}$ untranslated region (3' UTR) of the targeted transcript (Lee et al. 1993, Bartel 2009). Once miRISC is bound to the 3' UTR of the targeted transcript, miRISC interferes with gene expression via blocking translation (Ha \& Kim 2014) (Fig. 1A).

Another developmentally important sRNA species harboured by spermatozoa are the endogenous siRNAs (endo-siRNAs) (Song et al. 2011). Double-stranded RNA transcripts of perfect complementarity serve as precursor substrates for endo-siRNA production. These substrates are exported to the cytoplasm where they are processed by DICER to produce a mature endo-siRNA (Song et al. 2011). Once liberated from its precursor, the mature endo-siRNA is loaded into AGO2 to form an active siRISC to target mRNAs that harbour highly complementary sequences for endonucleolytic cleavage (Czech et al. 2008, Kawamura et al. 2008) (Fig. 1B). Research performed to date in plants, yeast and more recently flies, has revealed that this class of regulatory sRNA directs an additional function as an epigenetic regulator, via either RNA-directed DNA methylation (RdDM), or chromatin modification (Fagegaltier et al. 2009, Verdel et al. 2009). However, whether spermatozoa harboured endo-siRNAs are involved in an analogous pathway in animals remains to be determined. Nevertheless, spermborne endo-siRNA-directed gene expression regulation has been linked to critical early embryo development events in mice (Yuan et al. 2016).

Interestingly, distinct to the predominance of the miRNA class of sRNA in caput sperm, the most abundant sRNA class harboured by mature cauda sperm, are the tRFs, or tRNA-derived fragments (Sharma et al. 2016, Hutcheon et al. 2017). Transcription and processing of a precursor tRNA (pre-tRNA) transcript occurs within the nucleus to produce a mature tRNA (Fig. 1C). Once exported to the cytoplasm, the tRNA is able to fulfil its primary function in protein translation on the ribosomes. However, beyond their fundamental role as a linker molecule in translation, the specific fragmentation of mature tRNA transcripts by the endonucleases angiogenin (ANG) and DICER to produce tRFs, affords 


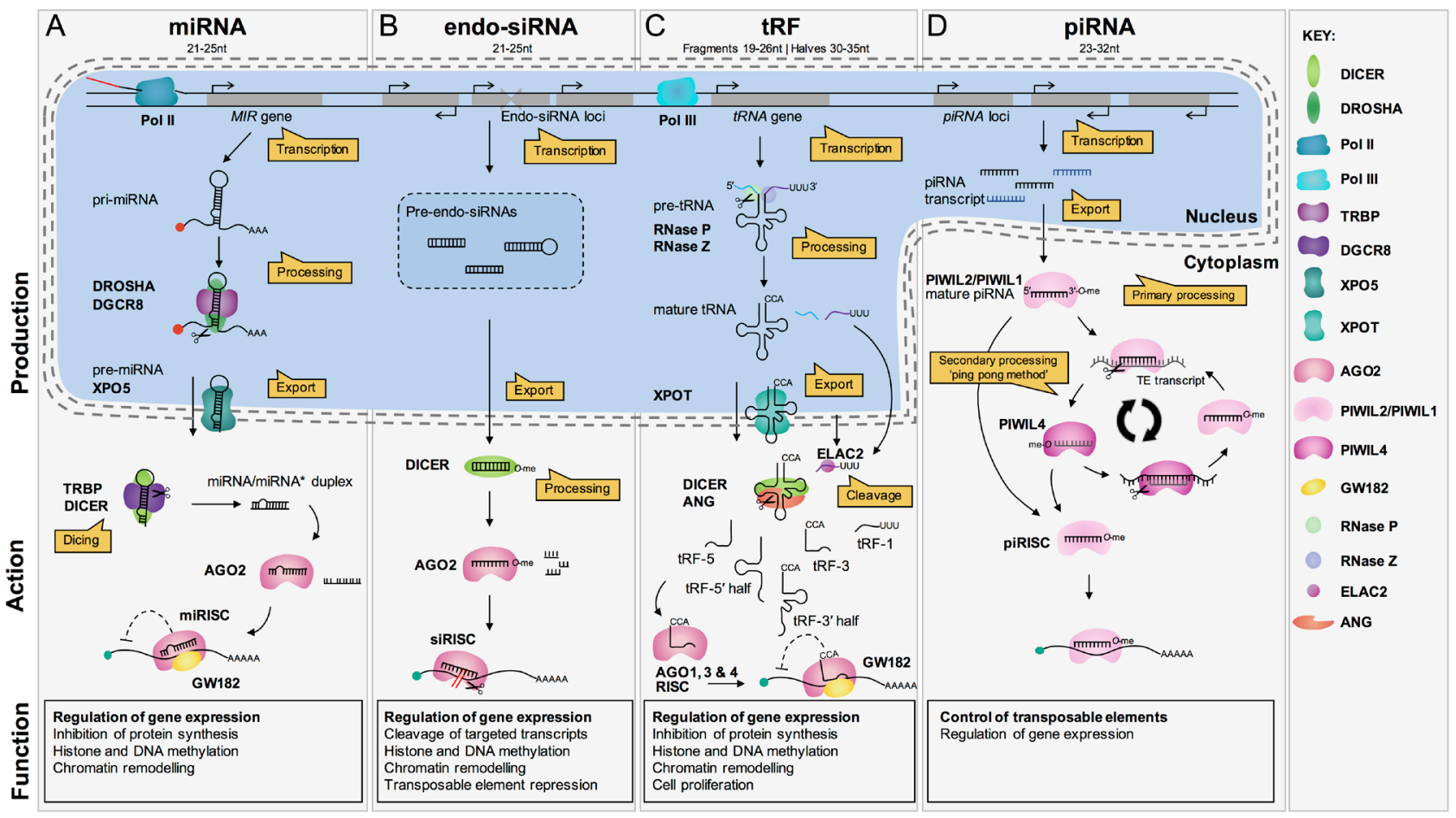

Figure 1 The production and function of small RNA species harboured by mouse spermatozoa. Mouse spermatozoa harbour a diverse repertoire of sRNAs, including miRNA, endo-siRNA, tRF and piRNA classes (Hutcheon et al. 2017). The individual steps involved in the production, and subsequent action, of each class of sRNA that accumulates in mouse spermatozoa is distinct. (A) miRNA: MIR genes are transcribed by RNA polymerase (Pol) II to form a primary-miRNA (pri-miRNA) and the pri-miRNA is processed by DROSHA and DGCR8 to generate the precursor miRNA (pre-miRNA) (Lee et al. 2003). Post pre-miRNA nuclear export by exportin-5 (XPO5) (Yi et al. 2003), the pre-miRNA is processed by DICER and TRBP to generate the miRNA/miRNA* duplex (Haase et al. 2005), and either duplex strand is loaded into ARGONAUTE2 (AGO2) to form miRISC. Together with protein, GW182, miRISC represses miRNA target transcript translation (reviewed in Ha \& Kim 2014). (B) EndoSiRNA: perfectly dsRNA molecules serve as endo-siRNA precursors (pre-endo-siRNA), and post nuclear export, the pre-endo-siRNA is processed by DICER to produce a siRNA/siRNA* duplex. Either duplex strand is loaded by AGO2 to form siRISC, and siRISC regulates siRNA target gene expression via AGO2-catalysed mRNA cleavage (Song et al. 2011). (C) $t R F$ : precursor tRNAs (pre-tRNA) are transcribed from $t R N A$ genes by RNA Pol III, and are subsequently processed by RNase P and RNase Z prior to nuclear export by exportin-T (XPOT). Mature tRFs are generated directly by the action of angiogenin (ANG), or via further DICER processing (Cole et al. 2009, Fu et al. 2009). The resulting tRF is loaded into AGO1, AGO3 or AGO4 to direct target gene translational repression. (D) piRNA: intergenic region-derived transcripts are loaded into PIWI proteins based on their 5' terminal nucleotide (Ishizu et al. 2012), and subsequently undergo $3^{\prime}$ to $5^{\prime}$ exonucleolytic trimming and 2'-O-methylation, to form mature primary piRNAs (Kirino \& Mourelatos 2007). The primary piRNA is then either; (1) loaded directly into RISC to target transcripts for cleavage-mediated silencing, or; (2) used by other PIWI proteins (PIWIL2/PIWIL1) to direct cleavage-mediated silencing of transposable element (TE)-derived transcripts in the secondary piRNA production pathway, the piRNA 'ping-pong' pathway (Iwasaki et al. 2015).

a new regulatory role to these once thought static contributors to gene expression (Cole et al. 2009, Fu et al. 2009, Lee et al. 2009). Post production, mature tRFs are loaded into AGO-catalysed RISC and thereafter direct either transcriptional or translational repression, by targeting the promoter region, or the $5^{\prime}$ UTR, of a targeted gene/target gene transcript. Such activity has, in turn, been linked to either transcriptional or translational repression of maternal transcripts in the embryo post fertilisation (Chen et al. 2016a, Schuster et al. 2016a).

Genomic integrity is of particular importance in the gamete destined to form a new organism. In terms of transposon or retrotransposon activity, the genome is afforded protection by an additional species of sRNA, the piRNAs. The piRNA production pathway occurs via a DICER-independent mechanism. Namely, nascent single-stranded RNAs transcribed from intergenic regions of the genome are loaded into PIWI (P-element induced wimpy testes) proteins (Ishizu et al. 2012), with the PIWI-loaded transcript subsequently undergoing $3^{\prime}$ to $5^{\prime}$ exonucleolytic trimming and 2'-O-methylation at the $3^{\prime}$ terminus to form a mature, primary piRNA (Kirino \& Mourelatos 2007). Primary piRNAs can on occasion, trigger the generation of secondary piRNA sRNAs via a production pathway known as the ping-pong cycle (Iwasaki et al. 2015) (Fig. 1D). The main function of piRNAs to mediate suppression of retrotransposon activity is particularly important in the context of spermatogenesis and is also of central relevance during early embryogenesis (Carmell et al. 2007). However, the role of piRNAs extends beyond this canonical regulatory function to gene expression regulation via modulation 
of the epigenetic status of protein-coding genes (Aravin et al. 2008, Thomson \& Lin 2009).

\section{Spermatozoa harbour a diverse small RNA profile that is potentially delivered to the oocyte at fertilisation}

Due to the transcriptionally and translationally inert state of spermatozoa, the RNA transcripts identified in this cell type were originally thought to be inconsequential remnants of untranslated mRNA stores generated during spermatogenesis. However, it is now understood that sperm sRNAs actively contribute to sperm function, early embryo development and transgenerational epigenetic inheritance. Therefore, sRNAs may potentially hold diagnostic value for assessment of the fertility status of a male (Salas-Huetos et al. 2016). This potential has served as a catalyst for several recent studies that utilised either a microarray or high-throughput sequencing approach to catalogue the RNA profile of spermatozoa. Such an approach not only confirmed a complex protein-coding RNA profile for sperm (i.e. mRNA transcripts; Miller \& Ostermeier 2006), but additionally documented, numerous species of non-protein-coding RNA, including numerous classes of sRNA (Ostermeier et al. 2005, Krawetz et al. 2011). Indeed, as documented earlier, the sRNAs that accumulate in mature spermatozoa include an abundance of miRNAs, endo-siRNAs, tRFs and piRNAs, as well as numerous additional sRNA molecules derived from the snRNA, snoRNA and rRNA molecules (Krawetz et al. 2011, Song et al. 2011, Peng et al. 2012). In recognition of increased interest in sperm-borne RNAs, a comprehensive database featuring expression data for both the large (>200 nt) and small (<200 nt) RNAs identified in the spermatozoa of several model species has been curated (SpermBase; Schuster et al. 2016b). The searchable SpermBase repository contains data for mouse, rat, rabbit and human spermatozoa, making it a particularly valuable resource for assessment of cross-species conservation of sperm RNA profiles.

While the biological significance of each of the thousands of distinct sperm-borne RNA species delivered to the oocyte remains to be determined, there is nonetheless growing evidence that highlights the importance of sRNAs in influencing the trajectory of early embryo development and the subsequent later life health of offspring (Chen et al. 2016b, Guo et al. 2017). One notable example is miRNA, $m i R-34 C$, which ranks amongst the most abundant miRNAs in human spermatozoa, and a miRNA that is also present in mouse spermatozoa and zygotes, but not in unfertilised female gametes in either of these species (Liu et al. 2012). Detailed analysis of miR-34c revealed that this miRNA may direct an essential role in regulating the first embryonic cleavage event following fertilisation (Liu et al. 2012). However, subsequent studies have shown that the sperm of mice harbouring a knockout mutation in the miR-34c encoding sequence retain their ability to fertilise oocytes and support normal embryonic development, thus casting doubt on the 'actual' biological role of this miRNA in both sperm development and oocyte fertilisation (Yuan et al. 2015). Subsequent studies have expanded on this theme, utilising strategies such as the germline-specific ablation of the DICERencoding gene, the endonuclease responsible for miRNA, endo-siRNA and tRF production (Song \& Rossi 2017). This conditional knockout mouse model produced spermatozoa partially deficient in miRNA and endo-siRNA production, and which additionally failed to support normal preimplantation embryonic development (Yuan et al. 2016). However, the same study demonstrated that this detrimental phenotype could be rescued via microinjecting fertilised oocytes with the total RNA pool extracted from the spermatozoa of wild-type males (Yuan et al. 2016).

\section{The small RNA profile of spermatozoa is markedly altered during epididymal transit}

Spermatozoa leave the testis harbouring a defined sRNA profile consisting of thousands of sequences mapping to all the major sRNA classes (Jodar et al. 2013, Sharma et al. 2016). Notably however, the sRNA landscape of spermatozoa is by no means static. Instead, the sperm sRNA profile undergoes considerable remodelling during the post-testicular maturation of these cells within the epididymis (Fig. 2A). In tracking the spatiotemporal distribution of the major classes of sperm sRNA, it has been shown that a proportion of sRNAs are maintained at their post-testicular levels as sperm transit the epididymis, while the composition of the remainder of the sRNA pool is altered (Nixon et al. 2015, Sharma et al. 2016). Illustrative of this remodelling, miRNAs account for approximately half of the global sRNA population of immature spermatozoa that are delivered into the caput epididymis. By comparison, the contribution of miRNAs amounts to only $\sim 16 \%$ of the global sRNA population of mature spermatozoa isolated from the distal cauda segment of the epididymis. Coincident with the reduction in miRNA abundance, tRF accumulation returns a reciprocal abundance trend, with the tRF class accounting for $65 \%$ of the total sRNA population of cauda sperm: equating to an almost three-fold elevation in abundance compared to caput spermatozoa (24\%) (Peng et al. 2012, Sharma et al. 2016, Hutcheon et al. 2017). Further, the abundance of each of the other sRNA classes is also altered during epididymal transit, with notable decreases in abundance to the snoRNA, snRNA and rRNA sRNA classes, and a substantial enrichment to the piRNA sRNA class in cauda sperm (Hutcheon et al. 2017) (Fig. 2A).

Remodelling of the sperm sRNA profile during their epididymal transit has recently been linked to the 

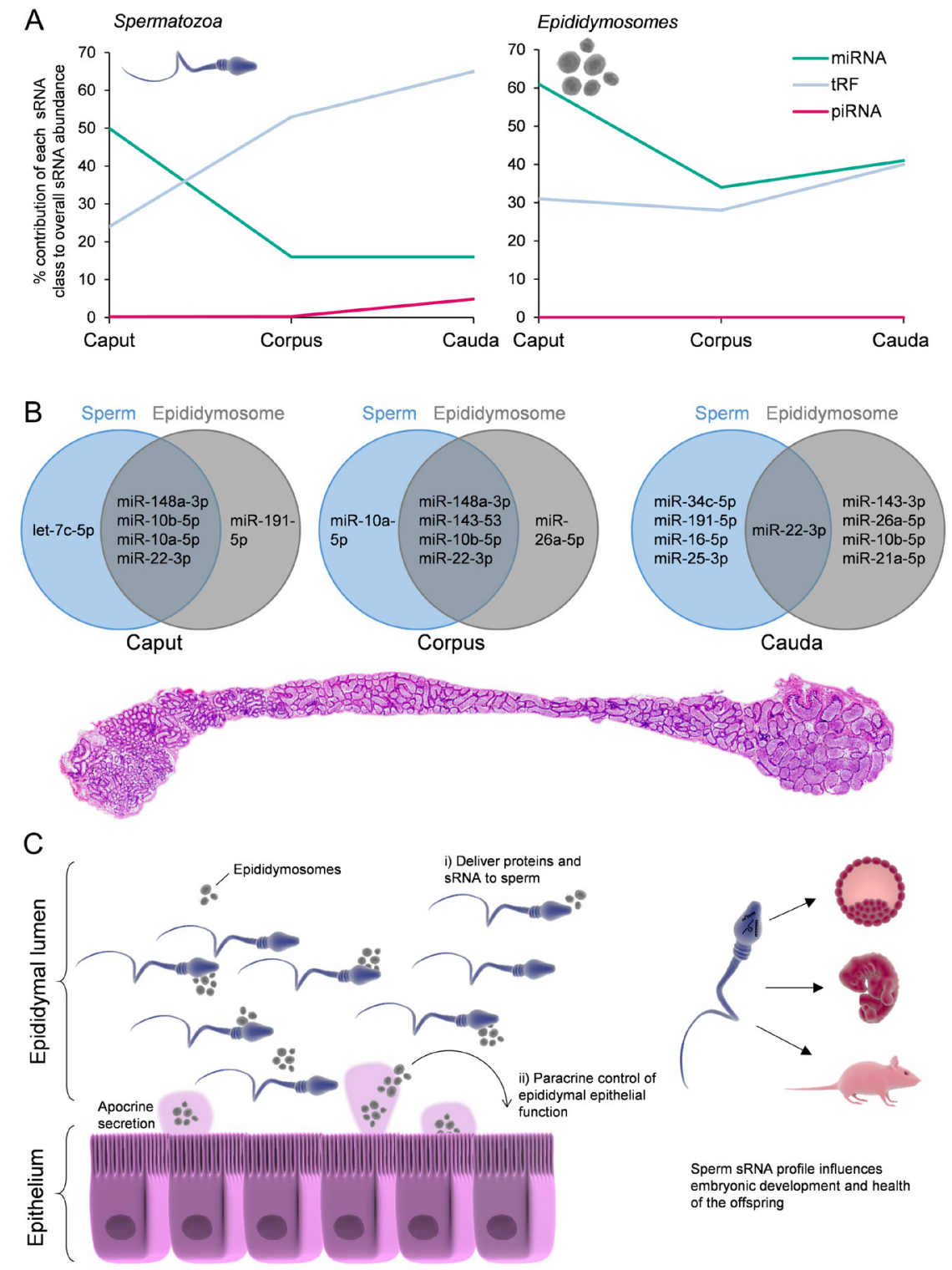

Figure 2 Epididymosomes modulate the sperm epigenome during epididymal transit. (A) The proportion of the three prominent small RNA (sRNA) classes implicated in transgenerational inheritance, microRNAs (miRNA), transfer RNA-derived fragments (tRFs) and PIWI interacting RNAs (piRNA). The line graphs depict the percentage of each of the sRNA classes contributing to the overall sRNA population in sperm (left) and epididymosomes (right) sampled from the caput, corpus and cauda mouse epididymis. (B) Venn diagrams illustrating the five most abundant miRNAs in sperm and epididymosomes sampled from the caput, corpus, and cauda segments of adult mouse epididymis. (C) Epididymosomes are released from the epididymal epithelium by apocrine secretion into the epididymal lumen. In the lumen, epididymosomes are able to, (i) interact with transiting spermatozoa and deliver cargo, including sRNA and (ii) effect a form of paracrine regulation by interacting with neighbouring epithelial cells. Epididymosomes play a role in modulating the sRNA profile of sperm, as they transit the epididymis. The population of sperm sRNA is subsequently delivered to the oocyte upon fertilisation and influences embryonic development and the health of the offspring. Figure adapted from Nixon et al. (2015), Reilly et al. (2016), Hutcheon et al. (2017) and Zhou et al. (2018).

functional transformation of the sperm cell (Conine et al. 2018). Specifically, embryos generated using intracytoplasmic sperm injection (ICSI) of immature caput sperm displayed signatures of aberrant preimplantation signalling and, as a consequence, consistently failed to implant. Notably, no such defects were observed in embryos generated using either cauda epididymal spermatozoa or those sampled from the testis. Furthermore, and of considerable interest, was the authors demonstration that these phenotypic aberrations were ameliorated via the co-injection of embryos with the sRNA cargo extracted from cauda epididymosomes (Conine et al. 2018). In contrast to this recent finding however, are the previous studies that reported that sperm isolated from the caput epididymis of mice (Suganuma et al. 2005), as well as sperm harvested from the human 
testis (Greco et al. 2005, Weissman et al. 2008), are capable of supporting fertilisation and embryonic development following ICSI, despite harbouring contrasting sRNA profiles (Hutcheon et al. 2017, Sharma et al. 2018). At present, the reason(s) for these apparently contradictory results remain to be determined.

Whilst we clearly still have much to learn about the physiological importance of the reshaping of the sperm sRNA profile as these cells traverse the epididymis, we also remain unsure of the precise mechanisms responsible for driving these alterations. One plausible explanation for the apparent reduction in individual miRNAs, and potentially other classes of sRNAs, is that these transcripts are packaged within the cytoplasmic droplet (Nixon et al. 2015); a remnant of the germ cell cytoplasm, which remains adhered to the neck region of testicular spermatozoa, but thereafter, gradually migrates distally along the tail before being shed from mature spermatozoa. Thus, by the time murine spermatozoa reach the cauda epididymis, only approximately half the population still possess cytoplasmic droplets and their encapsulated cargo. More enigmatic however, are the mechanism(s) responsible for sRNA acquisition during epididymal transit, particularly given that spermatozoa are transcriptionally quiescent and therefore incapable of the de novo production of sRNA precursor molecules. Spermatozoa must therefore rely on an alternate extrinsic mechanism, with potentially important contributions being made by the epididymal luminal environment in which the sperm are bathed. One possible route for sperm sRNA acquisition is delivery via RNA-binding proteins (RBPs): a sRNA transport route documented in other tissues (Wang et al. 2010, Arroyo et al. 2011). Indeed, the RBP class of protein have previously been assigned numerous roles in spermatogenesis (Sutherland et al. 2015). An important advantage afforded by sRNA loading by RBPs, such as binding with either AGO2 or nucleophosmin1 (NPM1), is that such a proteinbound state would provide protection from luminal RNases (Wang et al. 2010, Hoy \& Buck 2012). Currently however, little is known about the presence and/or abundance of RBPs in the epididymal lumen, or their potential for association with maturing spermatozoa. Rather, owing to pioneering studies conducted by Sullivan and colleagues, an alternative mode of sRNA delivery involving their encapsulation in extracellular vesicles, specifically epididymosomes, has attracted the balance of attention in this field (Belleannée et al. 2013, Sullivan \& Saez 2013). Thus, while RBP-mediated sRNA transport remains a possibility within the epididymis, and worthy of further investigation, for the purpose of this review, here we will only focus on epididymosomemediated inter-cellular communication, and bulk delivery of sRNA cargo to spermatozoa transiting the epididymis.

\section{The contribution of epididymosomes to the altered small RNA profile of epididymal spermatozoa}

Epididymosomes are broadly defined as membrane bound extracellular vesicles (EVs) that are produced within the principal cells of the epididymal epithelium (Fig. 2C). Noting that epididymosomes have a diameter in the range of between 50 and $150 \mathrm{~nm}$ (Frenette et al. 2010) and contain an abundance of proteomic cargo typical of small EV subtypes (Girouard et al. 2011, Nixon et al. 2018), these entities are generally classified as exosomes (Lötvall et al. 2014). However, epididymosomes do display some degree of heterogeneity, both in terms of their encapsulation of defined exosomal markers, such as CD9 and other tetraspanin partners, and also in their capacity to interact with target cells (Frenette et al. 2010), thus making definitive classification difficult (Sullivan 2015). Moreover, epididymosomes are delivered to the epididymal lumen via an apocrine secretory pathway that involves the formation of large blebs at the apical margin of the parent cell. After narrowing of the processes attaching these apical blebs to their parent cells, they eventually detach and subsequently fragment releasing their contents into the extracellular compartment (Hermo \& Jacks 2002).

In the epididymis, bleb disintegration leads to the release of encapsulated epididymosomes, along with other cellular-derived content, into the epididymal lumen. Following their release, epididymosomes are able to interact with neighbouring epithelial cells to affect a form of paracrine regulation, thereby indirectly influencing sperm maturation via maintenance of the complex epididymal luminal milieu (Belleannée et al. 2013). Alternatively, epididymosomes are also brought into close apposition with luminal spermatozoa to exert a more direct influence on sperm maturation via delivery of fertility modulating cargo to these recipient cells (Sullivan \& Saez 2013, Martin-DeLeon 2015). Since their initial discovery in the hamster (Yanagimachi et al. 1985), epididymosomes have been identified in the reproductive tract of a number of other species including the bull (Frenette \& Sullivan 2001), mouse (Rejraji et al. 2006), ram (Ecroyd et al. 2004), cat (Rowlison et al. 2018) and human (Thimon et al. 2008). Furthermore, the interaction between epididymosomes and sperm is now a widely accepted means by which to deliver a complex proteomic and lipidomic payload to maturing spermatozoa (Frenette et al. 2002, Rejraji et al. 2006).

Exosome-mediated cell-to-cell communication is well characterised in many biological systems. In comparison however, research into this vesicle-dependent mechanism of molecular transport in the male reproductive tract is relatively scarce. Nevertheless, the balance of evidence indicates that epididymosome-sperm interactions are likely to be selective, with epididymosome proteins 
having been shown to be preferentially transferred to the post-acrosomal domain of the sperm head (Nixon et al. 2018) before putatively being distributed in a bidirectional manner to the anterior region of the head and mid-piece of the flagellum (Frenette et al. 2005). This selectivity raises the prospect that the composition of the sperm plasma membrane and/or the epididymosomes themselves may influence the efficacy of their union, with specialised membrane micro domains known as lipid rafts having been implicated in the coordination of initial epididymosome-sperm interactions (Girouard et al. 2009). Accordingly, these micro domains are highly enriched in cholesterol and sphingolipid (Harroun et al. 2008) and serve to compartmentalize GPI-anchored proteins such as P25b and SPAM1 (Griffiths et al. 2008), which themselves have been implicated in epididymosome-sperm adhesion. In this context, the proteolytic release of GPI-linked proteins from the sperm lipid rafts leads to a significant reduction in the efficacy of epididymosome cargo transfer to the sperm cells (Girouard et al. 2009). Moreover, it has been shown that extensive remodelling of the lipid membrane of both epididymosomes and spermatozoa occurs along the length of the epididymis, with the epididymosome lipid bilayer being characterised by progressive increases in rigidity, and the sperm plasma membrane displaying the opposing trend of increased fluidity (Rejraji et al. 2006). Such changes are believed to favour the transfer of lipids from epididymosomes to sperm, a finding supported by the uptake of labelled lipids ( $\mathrm{DilCl} 2)$ from bovine epididymosomes to spermatozoa in vitro (Caballero et al. 2013).

Despite this evidence, the absence of major epididymosome membrane-bound proteins in spermatozoa suggests that epididymosome-sperm interactions do not encompass a complete fusion event (Gatti et al. 2005). Similarly, it has been suggested that endocytic uptake, one of the principal routes for exosome internalisation in somatic cells (Mulcahy et al. 2014), is unlikely to occur in mature spermatozoa (Jones et al. 2013). This is because spermatozoa lack both the machinery needed to internalise exogenous molecules via endocytosis and the lysosomal organelles to which endocytosed cargo are typically targeted (Jones et al. 2013). Rather, epididymosome adherence may be followed by the creation of a transient fusion pore and subsequent release of the epididymosome once delivery of their cargo is complete. Accordingly, proteomic analyses of epididymosomes, and spermatozoa themselves, have identified a myriad of complementary trafficking proteins (including SNARE proteins, Ras-like proteins and dynamins) (Girouard et al. 2011, Nixon et al. 2018) that could regulate this form of intercellular communication. This model may, in part, account for why a portion of epididymosomes persist in seminal fluids rather than being completely absorbed by spermatozoa within the duct. While there is currently limited functional evidence linking any of these trafficking proteins to a role in sperm-epididymosome interaction, immunoelectron microscopy analysis has confirmed the presence of stalk-like projections forming at the interface of epididymosome-spermatozoa contact (Nixon et al. 2018). Similar ultrastructural features are also witnessed between spermatozoa and oviductosomes (extracellular membrane vesicles released into the oviductal fluid) (Al-Dossary et al. 2015), raising the prospect of conserved mechanisms for facilitating cargo delivery between spermatozoa and the different populations of extracellular vesicles they encounter during their journey to the site of fertilisation. Consistent with these findings, the transfer of epididymosome proteins can be significantly inhibited by antibody masking of MFGE8, a protein that possesses a RGD recognition motif implicated in integrin/ligand interactions that proceed cellular fusion (Raymond et al. 2009, Nixon et al. 2018). Regardless of their mechanism of uptake, epididymosome interactions culminate in significant compositional modifications of the sperm membrane architecture and cytosolic domains (Griffiths et al. 2008, Schwarz et al. 2013). Further, the demonstrated ability of epididymosomes to encapsulate their ferried cargo within a protective lipid bilayer in the epididymal lumen identifies epididymosomes as an attractive vehicle to transport sRNA to transiting epididymal sperm.

Indeed, recent studies have begun to provide proof of principle that epididymosomes are capable of trafficking sRNA cargo to spermatozoa (Reilly et al. 2016), with deep sequencing analysis revealing a global increase in sRNA abundance in sperm following co-incubation with epididymosomes in vitro (Sharma et al. 2018). Hence, a role for epididymosomes in modulating the sRNA profile of sperm is possible (Eaton et al. 2015). Accordingly, analysis of epididymosomes sampled from specific segments along the length of the epididymis has revealed substantial modification to their sRNA cargo, many of which correspond with changes documented in spermatozoa, thereby providing correlative evidence to implicate these vesicles in influencing the epigenome of sperm during epididymal transit (Reilly et al. 2016, Hutcheon et al. 2017, Sharma et al. 2018) (Fig. 2B).

Analysis of the sRNA cargo of epididymosomes documented numerous sRNA species, including the miRNAs and tRFs as well as those sRNAs derived from snRNAs, snoRNAs and rRNAs (Hutcheon et al. 2017). Interestingly, the sRNAs encapsulated in epididymosomes are distinct to many of those harboured by their parent cells, a finding that indicates selective sRNA packaging by parent cells for subsequent release via epididymosomes (Belleannée et al. 2013, Reilly et al. 2016); a characteristic that is shared among exosomes released from non-reproductive tissues (Guduric-Fuchs et al. 2012). It is of particular interest to note here however, that mouse epididymosomes do not harbour substantial amounts of the piRNA sRNA 
class (Hutcheon et al. 2017), and co-incubation of epididymosomes and spermatozoa in vitro does not result in substantial piRNA transfer (Sharma et al. 2018). Thus, it is unlikely that epididymosomes account for the elevated accumulation of this sRNA class documented in mature cauda spermatozoa (Fig. 2A). Rather, the identification of proteins involved in piRNA production in cauda spermatozoa invites speculation that sperm may harbour precursor piRNA transcripts that can be used as substrates by pathway machinery proteins for piRNA production (Hutcheon et al. 2017).

Taken together, these data build a case for a role of epididymosomes in establishing the sperm sRNA profile during epididymal transit. However, as evidenced by work on the piRNA class of sRNA, the extent of this contribution potentially differs between each sRNA species. A recent perspective piece further extrapolated this role by suggesting that epididymal derived extracellular vesicles and their sRNA cargo are important in the transgenerational inheritance of environmental effects (Eaton et al. 2015). This role was suggested to involve epididymosomes facilitating communication between the exposed epididymal epithelium and the spermatozoa migrating through the epididymal lumen. Indeed, successive research has revealed that exposure to a number of environmental stressors can influence the sperm sRNA profile (Marczylo et al. 2012, Fullston et al. 2013, Gapp et al. 2014) and that epididymosomes are potential mediators of this altered sRNA accumulation profile (Sharma et al. 2016, Rompala et al. 2018).

\section{The role of epididymosomes in mediating an altered small RNA profile in spermatozoa in response to the environment}

It is now well established that the sRNA profile of sperm is altered in response to a changed environment. One of the first studies to examine this phenomenon utilised a high-throughput sequencing approach to reveal an increased accumulation of a subset of miRNAs, in addition to an opposing reduced accumulation of the piRNA class of sRNA, in mouse spermatozoa post-exposure to early life trauma in the form of unpredictable maternal separation in combination with unpredictable maternal stress (Gapp et al. 2014). Further, the offspring of exposed fathers displayed distinct behavioural phenotypes, including heightened fear and depressive-like behaviours. Via microinjection of the total RNA pool of sperm of traumatised mice into fertilised oocytes, the causal relationship of these responses was demonstrated. Such an approach successfully recapitulated the offspring phenotype; a demonstration that implicated sperm as the vector, and their RNA cargo as the causative agents, in this intergenerational inheritance model (Gapp et al. 2014). This demonstration also subsequently led to a series of studies that further explored this paradigm using other stress models (Table 1). Collectively, from the studies summarised in Table 1, it is now apparent that an array of paternal stressors, ranging from dietary perturbation (e.g. high fat, low protein), chronic psychological stress, ethanol consumption, environmental pollution and cigarette smoke exposure, can each differentially alter the sRNA profile of sperm of exposed males ( $\mathrm{Li}$ et al. 2012, Marczylo et al. 2012, Rodgers et al. 2013, Saavedra-Rodriguez \& Feig 2013, Gapp et al. 2014, Metzler-Guillemain et al. 2015, Paris et al. 2015, de Castro Barbosa et al. 2016, Donkin et al. 2016, Fullston et al. 2016, Murashov et al. 2016, Rompala et al. 2016, Sharma et al. 2016, Short et al. 2016, 2017, Benito et al. 2018, Dickson et al. 2018, Ingerslev et al. 2018, Rompala et al. 2018). Further, some of these studies went on to demonstrate that an altered sperm sRNA profile contributed to altered phenotypic outcomes in the offspring post fertilisation. For example, independent work by de Castro Barbosa et al. (2016) and Fullston et al. (2016) has provided evidence that fathers exposed to a high-fat diet produce spermatozoa with altered sRNA profiles and that the resulting offspring of these males express overt metabolic disturbances. However, an altered sperm sRNA profile is not always associated with negative phenotypic outcomes, with exercise intervention in mice leading to an anxiolytic behavioural phenotype in offspring (Short et al. 2017).

Whilst the majority of these studies have focused on defining the role of sperm-borne sRNAs as 'information carriers' in intergenerational inheritance models, determining the mechanism(s) by which the sperm sRNA profile is altered under conditions of stress remains an important area of investigation. Interestingly, altered abundance of several sperm miRNA and tRF sRNAs, including miR-375, miR-191-5p, miR-467e, tRF-GlyGCC and tRF-Glu-CTC, has been directly attributed to epididymosome-mediated transferral mechanisms via in vitro co-culture experiments (bolded text in Table 1 and; Reilly et al. 2016, Sharma et al. 2018). However, more compelling causal links implicating epididymosomes in this phenomenon have been established in recent reports that utilised the mouse model to study chronic ethanol consumption. Specifically, the tRF cargo of epididymosomes from mice exposed to this insult demonstrated equivalent alterations to those observed in their spermatozoa (Rompala et al. 2018). By providing the first evidence of a concomitant modification of the sRNA cargo of both epididymosome and sperm in response to paternal insult (Rompala et al. 2018), this study builds on earlier reports alluding to the importance of epididymosomes in conveying an altered tRF profile to the spermatozoa of males placed on a low-protein diet (Sharma et al. 2016).

To begin to explore whether conditions of stress converge to elicit a common dysfunction in epididymosome trafficking, or alternatively, whether 


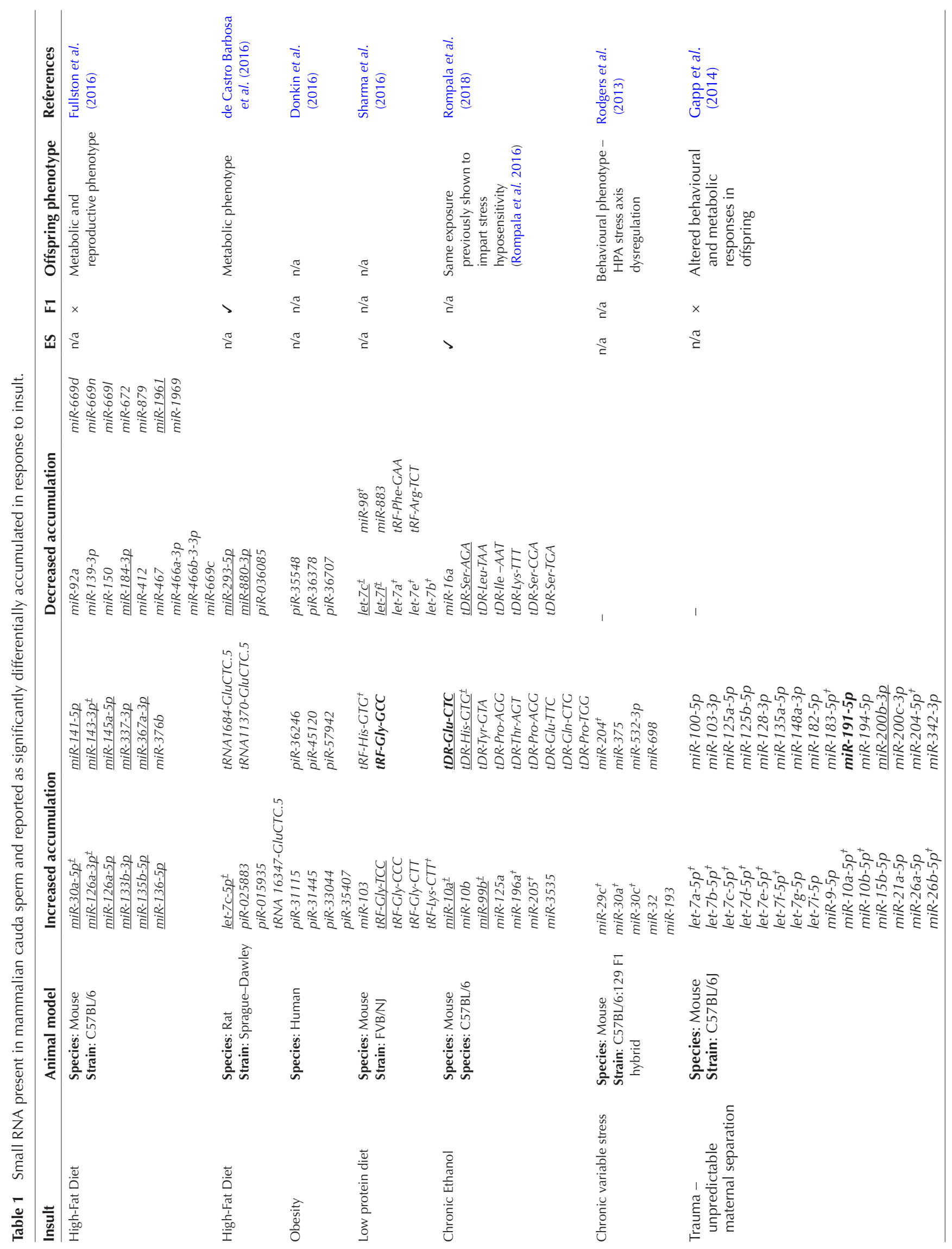




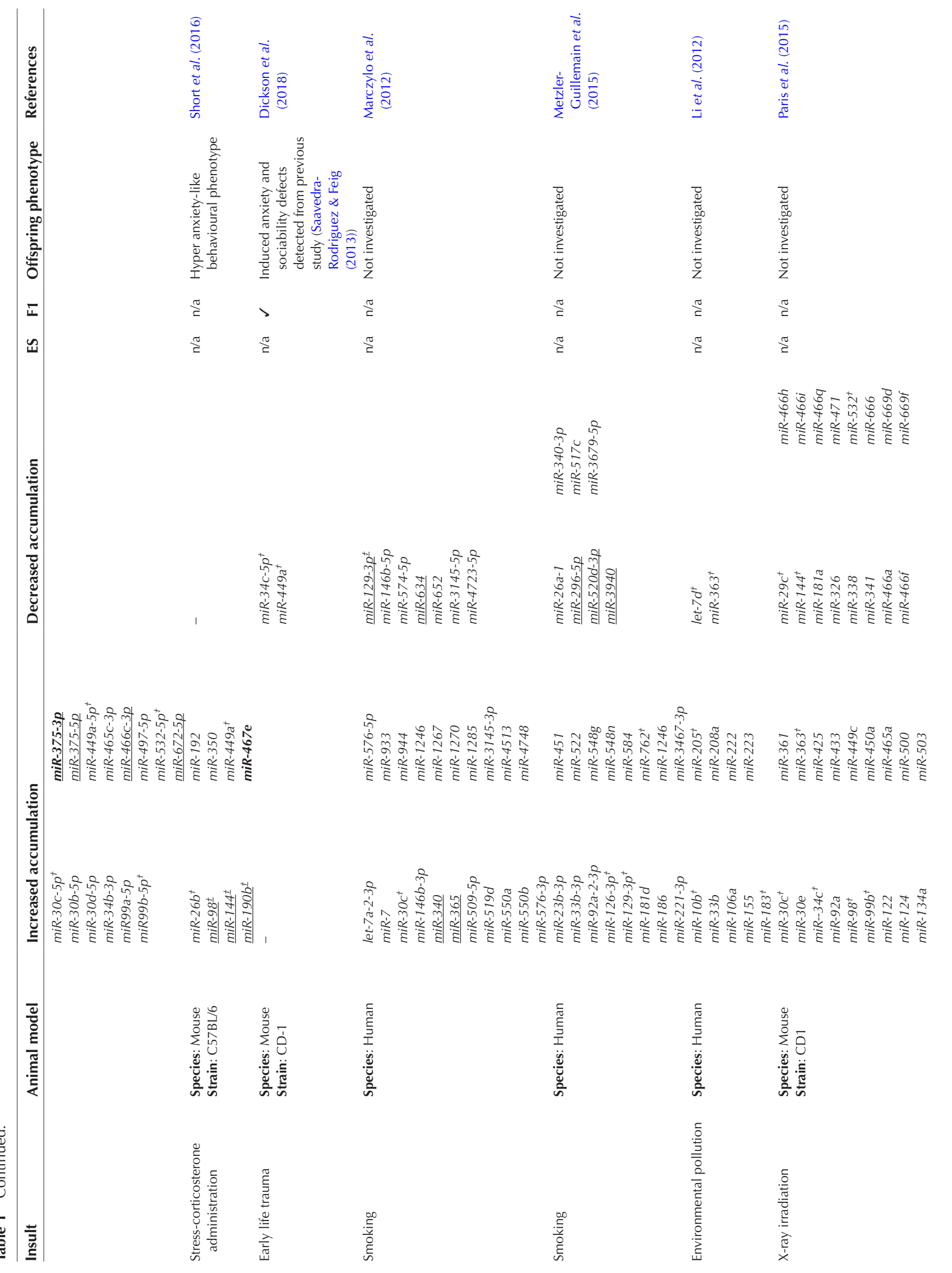



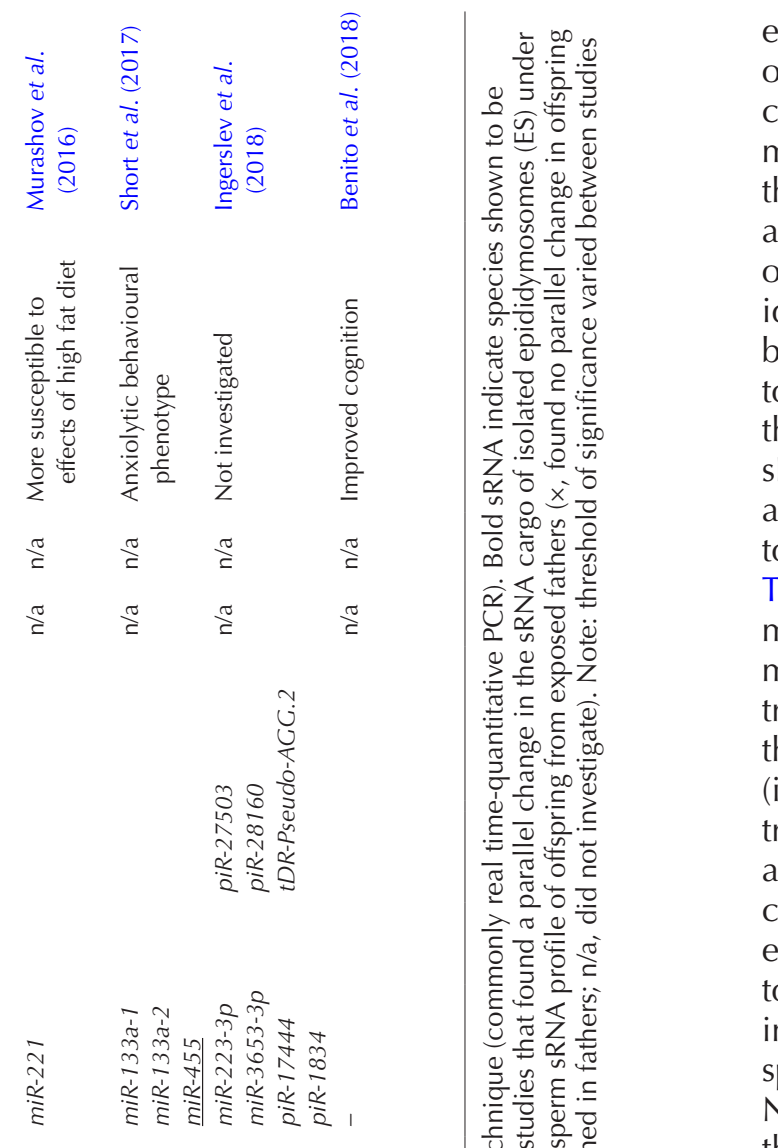

each stress drives unique alterations to the composition of the total sperm sRNA population, we surveyed the curated lists of sRNA profiles documented across multiple stress models (Table 1). Perhaps expectedly, this analysis revealed that each stress model displayed a divergent combination of changes to the sRNA profile of stressed sperm. Notably however, this analysis also identified a specific subset of sRNA species that have been reported to differentially accumulate in response to more than one environmental insult. Illustrative of this, among the 17 studies summarised in Table 1, 30 sRNAs, including 28 miRNAs repeatedly returned an altered change in abundance post-exposure of sperm to multiple environmental insults (denoted by ${ }^{+}$in Table 1). As a cautionary note, we emphasise that each miRNA has the ability to modulate the abundance of many numerous, functionally unrelated protein-coding transcripts, and thus, it is important to not over-interpret the significance of similar changes in sRNA abundance (i.e. the same sRNA and a matching abundance trend) post exposure to multiple stressors. Further, we acknowledge the variations in documented sperm sRNA changes arising from the application of similar stress exposure models in independent laboratories. The extent to which such variability is attributed to differences in experimental design, methodologies and/or model species/strains employed remains to be determined. Notwithstanding these caveats, our interrogation of the available literature provides preliminary evidence to suggest that each imposed stress results in a unique signature of altered sRNA abundance in exposed sperm. Considering this information, it is tempting to speculate that rather than simply being a legacy of reproductive tract dysfunction, these changes may hold some adaptive value (Rechavi \& Lev 2017). Indeed, this hypothesis has recently been promulgated on the basis of studies in invertebrate models, where it is suggested that males are able to transmit an adaptive advantage to subsequent generations (Rechavi et al. 2011, Wang et al. 2017). However, whether this paradigm is applicable to complex organisms, such as vertebrates, remains to be elucidated.

While epididymosomes potentially mediate the transfer of sRNA from the epididymal soma to maturing spermatozoa, these vesicles and their harboured cargo are produced within the epididymal epithelial cells. Therefore, under stress conditions, the physiology of the epididymal epithelial cells is likely altered; a physiological change that could initiate a series of biochemical events which result in an altered sRNA population being produced and packaged into the epididymosomes generated by stressed cells. Currently, this is not an active area of research focus within this field, however, with each individual insult demonstrated to elicit a unique change to the sRNA profile of sperm (Table 1), it is likely that the production and packaging of sRNAs into epididymosomes within the stressed 
epididymal epithelial cell, differs with each individual insult. To date, this paradigm has been considered in the context of chronic stress, where it has been suggested that exposure to elevated corticosterone modulates the expression of the glucocorticoid receptor, and this in turn promotes aberrant epididymal epithelial cell signalling (Pang et al. 2017). The dysregulation of intracellular signalling is, in part reflected by an altered miRNA production profile and packaging into epididymosomes, thus putatively driving equivalent changes to the sperm sRNA profile (Pang et al. 2017). Whilst plausible, this proposed model obviously requires experimental validation.

\section{Concluding remarks}

The sRNA profile of spermatozoa is now recognised as an important epigenetic contributor to early embryo development and subsequent offspring health. Indeed, the specific reshaping of this profile that occurs during epididymal transit is required to produce a mature spermatozoon that is not only capable of initiating fertilisation but also supporting early embryonic development and the generation of healthy offspring. However, the plasticity of the sRNA profile under conditions of stress and the consequences of an altered sRNA profile are becoming increasingly apparent. This therefore places heightened emphasis on the need to understand the mechanisms responsible for altering the sRNA landscape of sperm of stressed males. Among the most attractive mechanisms for modulating the global sRNA landscape of sperm under normal physiological conditions, and those encountered during episodes of stress, are epididymosomes. These specialised extracellular vesicles have been implicated in a novel form of intercellular communication, which is capable of dramatically altering the proteomic, lipidomic and epigenetic landscape of the maturing spermatozoon. What remain less certain are the underlying biological processes that drive alterations of the sRNA cargo of epididymosomes. Further research in this field promises to advance our currently limited understanding of the legacy of exposure to environmental insult on future generations and to inform rational therapeutic intervention strategies.

\section{Declaration of interest}

The authors declare that there is no conflict of interest that could be perceived as prejudicing the impartiality of this review.

\section{Funding}

This work was supported by the National Health and Medical Research Council (NHMRC) of Australia (grant numbers APP1103176 and APP1147932). N A Trigg is the recipient of an Australian Government Research Training Program (RTP) Scholarship.

\section{References}

Al-Dossary AA, Bathala P, Caplan JL \& Martin-DeLeon PA 2015 Oviductosome-sperm membrane interaction in cargo delivery: detection of fusion and underlying molecular players using three-dimensional super-resolution structure illumination microscopy (SR-SIM). Journal of Biological Chemistry 290 17710-17723. (https://doi.org/10.1074/jbc. M114.633156)

Ambros V, Bartel B, Bartel DP, Burge CB, Carrington JC, Chen X, Dreyfuss G, Eddy SR, Griffiths-Jones S, Marshall M et al. 2003 A uniform system for microRNA annotation. RNA 9 277-279. (https://doi. org/10.1261/rna.2183803)

Aravin AA, Sachidanandam R, Bourc'his D, Schaefer C, Pezic D, Fejes Toth KF, Bestor T \& Hannon GJ 2008 A piRNA pathway primed by individual transposons is linked to de novo DNA methylation in mice. Molecular Cell 31 785-799. (https://doi.org/10.1016/j. molcel.2008.09.003)

Arroyo JD, Chevillet JR, Kroh EM, Ruf IK, Pritchard CC, Gibson DF, Mitchell PS, Bennett CF, Pogosova-Agadjanyan EL, Stirewalt DL et al. 2011 Argonaute2 complexes carry a population of circulating microRNAs independent of vesicles in human plasma. PNAS $\mathbf{1 0 8}$ 5003-5008. (https://doi.org/10.1073/pnas.1019055108)

Bartel DP 2009 MicroRNAs: target recognition and regulatory functions. Cell 136 215-233. (https://doi.org/10.1016/j.cell.2009.01.002)

Belleannée C, Calvo É, Caballero J \& Sullivan R 2013 Epididymosomes convey different repertoires of microRNAs throughout the bovine epididymis. Biology of Reproduction 89 30. (https://doi.org/10.1095/ biolreprod.113.110486)

Benito E, Kerimoglu C, Ramachandran B, Pena-Centeno T, Jain G, Stilling RM, Islam MR, Capece V, Zhou Q, Edbauer D et al. 2018 RNAdependent intergenerational inheritance of enhanced synaptic plasticity after environmental enrichment. Cell Reports 23 546-554. (https://doi. org/10.1016/j.celrep.2018.03.059)

Caballero JN, Frenette G, Belleannée C \& Sullivan R 2013 CD9-positive microvesicles mediate the transfer of molecules to bovine spermatozoa during epididymal maturation. PLOS ONE 8 e65364. (https://doi. org/10.1371/journal.pone.0065364)

Carmell MA, Girard A, van de Kant HJ, Bourc'his D, Bestor TH, de Rooij DG \& Hannon GJ 2007 MIWI2 is essential for spermatogenesis and repression of transposons in the mouse male germline. Developmental Cell 12 503-514. (https://doi.org/10.1016/j.devcel.2007.03.001)

Chen Q, Yan M, Cao Z, Li X, Zhang Y, Shi J, Feng GH, Peng H, Zhang X, Zhang Y et al. 2016a Sperm tsRNAs contribute to intergenerational inheritance of an acquired metabolic disorder. Science 351 397-400. (https://doi.org/10.1126/science.aad7977)

Chen Q, Yan W \& Duan E $2016 b$ Epigenetic inheritance of acquired traits through sperm RNAs and sperm RNA modifications. Nature Reviews. Genetics 17 733-743. (https://doi.org/10.1038/nrg.2016.106)

Cole C, Sobala A, Lu C, Thatcher SR, Bowman A, Brown JW, Green PJ, Barton GJ \& Hutvagner G 2009 Filtering of deep sequencing data reveals the existence of abundant Dicer-dependent small RNAs derived from tRNAs. RNA 15 2147-2160. (https://doi.org/10.1261/rna.1738409)

Conine CC, Sun F, Song L, Rivera-Pérez JA \& Rando OJ 2018 Small RNAs gained during epididymal transit of sperm are essential for embryonic development in mice. Developmental Cell 46 470-480.e3. (https://doi. org/10.1016/j.devcel.2018.06.024)

Czech B, Malone CD, Zhou R, Stark A, Schlingeheyde C, Dus M, Perrimon N, Kellis M, Wohlschlegel JA, Sachidanandam R et al. 2008 An endogenous small interfering RNA pathway in Drosophila. Nature 453 798-802. (https://doi.org/10.1038/nature07007)

de Castro Barbosa T, Ingerslev LR, Alm PS, Versteyhe S, Massart J, Rasmussen M, Donkin I, Sjogren R, Mudry JM, Vetterli L et al. 2016 High-fat diet reprograms the epigenome of rat spermatozoa and transgenerationally affects metabolism of the offspring. Molecular Metabolism 5 184-197. (https://doi.org/10.1016/j. molmet.2015.12.002)

Dickson DA, Paulus JK, Mensah V, Lem J, Saavedra-Rodriguez L, Gentry A, Pagidas K \& Feig LA 2018 Reduced levels of miRNAs 449 and 34 in 
sperm of mice and men exposed to early life stress. Translational Psychiatry 8 101. (https://doi.org/10.1038/s41398-018-0146-2)

Donkin I, Versteyhe S, Ingerslev LR, Qian K, Mechta M, Nordkap L, Mortensen B, Appel EV, Jorgensen N, Kristiansen VB et al. 2016 Obesity and bariatric surgery drive epigenetic variation of spermatozoa in humans. Cell Metabolism 23 369-378. (https://doi.org/10.1016/j. cmet.2015.11.004)

Dunn GA \& Bale TL 2009 Maternal high-fat diet promotes body length increases and insulin insensitivity in second-generation mice. Endocrinology 150 4999-5009. (https://doi.org/10.1210/en.2009-0500)

Eaton SA, Jayasooriah N, Buckland ME, Martin DI, Cropley JE \& Suter CM 2015 Roll over Weismann: extracellular vesicles in the transgenerational transmission of environmental effects. Epigenomics 7 1165-1171. (https://doi.org/10.2217/epi.15.58)

Ecroyd H, Sarradin P, Dacheux JL \& Gatti JL 2004 Compartmentalization of prion isoforms within the reproductive tract of the ram. Biology of Reproduction 71 993-1001. (https://doi.org/10.1095/ biolreprod.104.029801)

Fagegaltier D, Bouge AL, Berry B, Poisot E, Sismeiro O, Coppee JY, Theodore L, Voinnet O \& Antoniewski C 2009 The endogenous siRNA pathway is involved in heterochromatin formation in Drosophila. PNAS 106 21258-21263. (https://doi.org/10.1073/pnas.0809208105)

Frenette G \& Sullivan R 2001 Prostasome-like particles are involved in the transfer of P25b from the bovine epididymal fluid to the sperm surface. Molecular Reproduction and Development 59 115-121. (https://doi org/10.1002/mrd.1013)

Frenette G, Lessard C \& Sullivan R 2002 Selected proteins of "prostasomelike particles" from epididymal cauda fluid are transferred to epididymal caput spermatozoa in bull. Biology of Reproduction 67 308-313. (https://doi.org/10.1095/biolreprod67.1.308)

Frenette G, Légaré C, Saez F \& Sullivan R 2005 Macrophage migration inhibitory factor in the human epididymis and semen. Molecular Human Reproduction 11 575-582. (https://doi.org/10.1093/molehr/gah197)

Frenette G, Girouard J, D'Amours O, Allard N, Tessier L \& Sullivan R 2010 Characterization of two distinct populations of epididymosomes collected in the intraluminal compartment of the bovine cauda epididymis. Biology of Reproduction 83 473-480. (https://doi. org/10.1095/biolreprod.109.082438)

Fu H, Feng J, Liu Q, Sun F, Tie Y, Zhu J, Xing R, Sun Z \& Zheng X 2009 Stress induces tRNA cleavage by angiogenin in mammalian cells. FEBS Letters 583 437-442. (https://doi.org/10.1016/j. febslet.2008.12.043)

Fullston T, Ohlsson Teague EM, Palmer NO, DeBlasio MJ, Mitchell M, Corbett M, Print CG, Owens JA \& Lane M 2013 Paternal obesity initiates metabolic disturbances in two generations of mice with incomplete penetrance to the F2 generation and alters the transcriptional profile of testis and sperm microRNA content. FASEB Journal 27 4226-4243. (https://doi.org/10.1096/fj.12-224048)

Fullston T, Ohlsson-Teague EM, Print CG, Sandeman LY \& Lane M 2016 Sperm microRNA content is altered in a mouse model of male obesity, but the same suite of microRNAs are not altered in offspring's sperm. PLoS ONE 11 e0166076. (https://doi.org/10.1371/journal.pone.0166076)

Gapp K, Jawaid A, Sarkies P, Bohacek J, Pelczar P, Prados J, Farinelli L, Miska E \& Mansuy IM 2014 Implication of sperm RNAs in transgenerational inheritance of the effects of early trauma in mice. Nature Neuroscience 17 667-669. (https://doi.org/10.1038/nn.3695)

Gatti JL, Métayer S, Belghazi M, Dacheux F \& Dacheux JL 2005 Identification, proteomic profiling, and origin of ram epididymal fluid exosome-like vesicles. Biology of Reproduction 72 1452-1465. (https:// doi.org/10.1095/biolreprod.104.036426)

Girouard J, Frenette G \& Sullivan R 2009 Compartmentalization of proteins in epididymosomes coordinates the association of epididymal proteins with the different functional structures of bovine spermatozoa. Biology of Reproduction 80 965-972. (https://doi.org/10.1095/ biolreprod.108.073551)

Girouard J, Frenette G \& Sullivan R 2011 Comparative proteome and lipid profiles of bovine epididymosomes collected in the intraluminal compartment of the caput and cauda epididymidis. International Journal of Andrology 34 e475-e486. (https://doi.org/10.1111/j.13652605.2011.01203.x)

Grandjean V, Fourré S, De Abreu DAF, Derieppe MA, Remy J \& Rassoulzadegan M 2015 RNA-mediated paternal heredity of diet- induced obesity and metabolic disorders. Scientific Reports 518193. (https://doi.org/10.1038/srep18193)

Greco E, Scarselli F, lacobelli M, Rienzi L, Ubaldi F, Ferrero S, Franco G, Anniballo N, Mendoza C \& Tesarik J 2005 Efficient treatment of infertility due to sperm DNA damage by ICSI with testicular spermatozoa. Human Reproduction 20 226-230. (https://doi.org/10.1093/humrep/deh590)

Griffiths GS, Galileo DS, Reese K \& Martin-Deleon PA 2008 Investigating the role of murine epididymosomes and uterosomes in GPI-linked protein transfer to sperm using SPAM1 as a model. Molecular Reproduction and Development 75 1627-1636. (https://doi.org/10.1002/mrd.20907)

Guduric-Fuchs J, O'Connor A, Camp B, O'Neill CL, Medina RJ \& Simpson DA 2012 Selective extracellular vesicle-mediated export of an overlapping set of microRNAs from multiple cell types. BMC Genomics 13 357. (https://doi.org/10.1186/1471-2164-13-357)

Guo L, Chao SB, Xiao L, Wang ZB, Meng TG, Li YY, Han ZM, Ouyang YC, Hou Y, Sun QY et al. 2017 Sperm-carried RNAs play critical roles in mouse embryonic development. Oncotarget 8 67394-67405. (https:// doi.org/10.18632/oncotarget.18672)

Ha M \& Kim VN 2014 Regulation of microRNA biogenesis. Nature Reviews Molecular Cell Biology 15 509-524. (https://doi.org/10.1038/nrm3838)

Haase AD, Jaskiewicz L, Zhang H, Laine S, Sack R, Gatignol A \& Filipowicz W 2005 TRBP, a regulator of cellular PKR and HIV-1 virus expression, interacts with Dicer and functions in RNA silencing. $E M B O$ Reports 6 961-967. (https://doi.org/10.1038/sj.embor.7400509)

Harroun TA, Katsaras J \& Wassall SR 2008 Cholesterol is found to reside in the center of a polyunsaturated lipid membrane. Biochemistry 47 7090-7096. (https://doi.org/10.1021/bi800123b)

Hermo L \& Jacks D 2002 Nature's ingenuity: bypassing the classical secretory route via apocrine secretion. Molecular Reproduction and Development 63 394-410. (https://doi.org/10.1002/mrd.90023)

Hoy AM \& Buck AH 2012 Extracellular small RNAs: what, where, why? Biochemical Society Transactions 40 886-890. (https://doi.org/10.1042/ BST20120019)

Hu HY, Yan Z, Xu Y, Hu H, Menzel C, Zhou YH, Chen W \& Khaitovich P 2009 Sequence features associated with microRNA strand selection in humans and flies. BMC Genomics 10 413. (https://doi.org/10.1186/14712164-10-413)

Hutcheon K, McLaughlin EA, Stanger SJ, Bernstein IR, Dun MD, Eamens AL \& Nixon B 2017 Analysis of the small non-protein-coding RNA profile of mouse spermatozoa reveals specific enrichment of piRNAs within mature spermatozoa. RNA Biology 14 1776-1790. (https://doi.org/10.10 80/15476286.2017.1356569)

Ingerslev LR, Donkin I, Fabre O, Versteyhe S, Mechta M, Pattamaprapanont P, Mortensen B, Krarup NT \& Barrès R 2018 Endurance training remodels sperm-borne small RNA expression and methylation at neurological gene hotspots. Clinical Epigenetics 1012. (https://doi.org/10.1186/s13148-018-0446-7)

Ishizu H, Siomi H \& Siomi MC 2012 Biology of piwi-interacting RNAs: new insights into biogenesis and function inside and outside of germlines. Genes and Development 26 2361-2373. (https://doi.org/10.1101/ gad.203786.112)

Iwasaki YW, Siomi MC \& Siomi H 2015 Piwi-interacting RNA: its biogenesis and functions. Annual Review of Biochemistry 84 405-433. (https://doi. org/10.1146/annurev-biochem-060614-034258)

Jodar M, Selvaraju S, Sendler E, Diamond MP, Krawetz SA \& Reproductive Medicine Network 2013 The presence, role and clinical use of spermatozoal RNAs. Human Reproduction Update 19 604-624. (https:// doi.org/10.1093/humupd/dmt031)

Jones S, Lukanowska M, Suhorutsenko J, Oxenham S, Barratt C, Publicover S, Copolovici DM, Langel Ü \& Howl J 2013 Intracellular translocation and differential accumulation of cell-penetrating peptides in bovine spermatozoa: evaluation of efficient delivery vectors that do not compromise human sperm motility. Human Reproduction $\mathbf{2 8}$ 1874-1889. (https://doi.org/10.1093/humrep/det064)

Kaati G, Bygren LO, Pembrey M \& Sjostrom M 2007 Transgenerational response to nutrition, early life circumstances and longevity. European Journal of Human Genetics 15 784-790. (https://doi.org/10.1038/ sj.ejhg.5201832)

Kawamura Y, Saito K, Kin T, Ono Y, Asai K, Sunohara T, Okada TN, Siomi MC \& Siomi H 2008 Drosophila endogenous small RNAs bind to Argonaute 2 in somatic cells. Nature 453 793-797. (https://doi. org/10.1038/nature06938) 
Kierszenbaum AL \& Tres LL 1975 Structural and transcriptional features of the mouse spermatid genome. Journal of Cell Biology 65 258-270. (https://doi.org/10.1083/jcb.65.2.258)

Kirino Y \& Mourelatos Z 2007 Mouse piwi-interacting RNAs are 2'-O-methylated at their 3' termini. Nature Structural and Molecular Biology 14 347-348. (https://doi.org/10.1038/nsmb1218)

Krawetz SA, Kruger A, Lalancette C, Tagett R, Anton E, Draghici S \& Diamond MP 2011 A survey of small RNAs in human sperm. Human Reproduction 26 3401-3412. (https://doi.org/10.1093/humrep/der329)

Lee RC, Feinbaum RL \& Ambros V 1993 The C. elegans heterochronic gene lin-4 encodes small RNAs with antisense complementarity to lin-14. Cell 75 843-854. (https://doi.org/10.1016/0092-8674(93)90529-Y)

Lee Y, Ahn C, Han J, Choi H, Kim J, Yim J, Lee J, Provost P, Radmark O, Kim S et al. 2003 The nuclear RNase III Drosha initiates microRNA processing. Nature 425 415-419. (https://doi.org/10.1038/ nature01957)

Lee YS, Shibata Y, Malhotra A \& Dutta A 2009 A novel class of small RNAs: tRNA-derived RNA fragments (tRFs). Genes and Development 23 2639-2649. (https://doi.org/10.1101/gad.1837609)

Li Y, Li M, Liu Y, Song G \& Liu N 2012 A microarray for microRNA profiling in spermatozoa from adult men living in an environmentally polluted site. Bulletin of Environmental Contamination and Toxicology 89 1111-1114. (https://doi.org/10.1007/s00128-012-0827-0)

Lim JP \& Brunet A 2013 Bridging the transgenerational gap with epigenetic memory. Trends in Genetics 29 176-186. (https://doi.org/10.1016/j. tig.2012.12.008)

Liu WM, Pang RT, Chiu PC, Wong BP, Lao K, Lee KF \& Yeung WS 2012 Sperm-borne microRNA-34c is required for the first cleavage division in mouse. PNAS 109 490-494. (https://doi.org/10.1073/ pnas.1110368109)

Lötvall J, Hill AF, Hochberg F, Buzás El, Di Vizio D, Gardiner C, Gho YS, Kurochkin IV, Mathivanan S, Quesenberry P et al. 2014 Minimal experimental requirements for definition of extracellular vesicles and their functions: a position statement from the International Society for Extracellular Vesicles. Journal of Extracellular Vesicles 3 26913-26913. (https://doi.org/10.3402/jev.v3.26913)

Marczylo EL, Amoako AA, Konje JC, Gant TW \& Marczylo TH 2012 Smoking induces differential miRNA expression in human spermatozoa: a potential transgenerational epigenetic concern? Epigenetics 7 432-439. (https://doi.org/10.4161/epi.19794)

Martin-DeLeon PA 2015 Epididymosomes: transfer of fertility-modulating proteins to the sperm surface. Asian Journal of Andrology 17 720-725. (https://doi.org/10.4103/1008-682X.155538)

Metzler-Guillemain C, Victorero G, Lepoivre C, Bergon A, Yammine M, Perrin J, Sari-Minodier I, Boulanger N, Rihet P \& Nguyen C 2015 Sperm mRNAs and microRNAs as candidate markers for the impact of toxicants on human spermatogenesis: an application to tobacco smoking. Systems Biology in Reproductive Medicine 61 139-149. (https://doi.org/10.3109 /19396368.2015.1022835)

Miller D \& Ostermeier GC 2006 Towards a better understanding of RNA carriage by ejaculate spermatozoa. Human Reproduction Update 12 757-767. (https://doi.org/10.1093/humupd/dml037)

Mulcahy LA, Pink RC \& Carter DR 2014 Routes and mechanisms of extracellular vesicle uptake. Journal of Extracellular Vesicles 3. (https:// doi.org/10.3402/jev.v3.24641)

Murashov AK, Pak ES, Koury M, Ajmera A, Jeyakumar M, Parker M, Williams O, Ding J, Walters D \& Neufer PD 2016 Paternal long-term exercise programs offspring for low energy expenditure and increased risk for obesity in mice. FASEB Journal 30 775-784. (https://doi. org/10.1096/fj.15-274274)

Nixon B, Stanger SJ, Mihalas BP, Reilly JN, Anderson AL, Tyagi S, Holt JE \& McLaughlin EA 2015 The microRNA signature of mouse spermatozoa is substantially modified during epididymal maturation. Biology of Reproduction 93 91. (https://doi.org/10.1095/biolreprod.115.132209)

Nixon B, De luliis GN, Hart HM, Zhou W, Mathe A, Bernstein I, Anderson AL, Stanger SJ, Skerrett-Byrne DA, Jamaluddin MFB et al. 2018 Proteomic profiling of mouse epididymosomes reveals their contributions to post-testicular sperm maturation. Molecular and Cellular Proteomics. (https://doi.org/10.1074/mcp.RA118.000946)

O'Brien J, Hayder H, Zayed Y \& Peng C 2018 Overview of microRNA biogenesis, mechanisms of actions, and circulation. Frontiers in Endocrinology 9 402. (https://doi.org/10.3389/fendo.2018.00402)
Ostermeier GC, Goodrich RJ, Moldenhauer JS, Diamond MP \& Krawetz SA 2005 A suite of novel human spermatozoal RNAs. Journal of Andrology 26 70-74. (https://doi.org/10.1002/j.1939-4640.2005.tb02874.x)

Pang TYC, Short AK, Bredy TW \& Hannan AJ 2017 Transgenerational paternal transmission of acquired traits: stress-induced modification of the sperm regulatory transcriptome and offspring phenotypes. Current Opinion in Behavioral Sciences 14 140-147. (https://doi.org/10.1016/j. cobeha.2017.02.007)

Paris L, Giardullo P, Leonardi S, Tanno B, Meschini R, Cordelli E, Benassi B, Longobardi MG, Izzotti A, Pulliero A et al. 2015 Transgenerational inheritance of enhanced susceptibility to radiationinduced medulloblastoma in newborn Ptch1(+/-) mice after paternal irradiation. Oncotarget 6 36098-36112. (https://doi.org/10.18632/ oncotarget.5553)

Peng H, Shi J, Zhang Y, Zhang H, Liao S, Li W, Lei L, Han C, Ning L, Cao Y et al. 2012 A novel class of tRNA-derived small RNAs extremely enriched in mature mouse sperm. Cell Research 22 1609-1612. (https:// doi.org/10.1038/cr.2012.141)

Raymond A, Ensslin MA \& Shur BD 2009 SED1/MFG-E8: a bi-motif protein that orchestrates diverse cellular interactions. Journal of Cellular Biochemistry 106 957-966. (https://doi.org/10.1002/jcb.22076)

Rechavi O \& Lev I 2017 Principles of transgenerational small RNA inheritance in Caenorhabditis elegans. Current Biology 27 R720-R730. (https://doi.org/10.1016/j.cub.2017.05.043)

Rechavi O, Minevich G \& Hobert O 2011 Transgenerational inheritance of an acquired small RNA-based antiviral response in C. elegans. Cell 147 1248-1256. (https://doi.org/10.1016/j.cell.2011.10.042)

Reilly JN, McLaughlin EA, Stanger SJ, Anderson AL, Hutcheon K, Church K, Mihalas BP, Tyagi S, Holt JE, Eamens AL et al. 2016 Characterisation of mouse epididymosomes reveals a complex profile of microRNAs and a potential mechanism for modification of the sperm epigenome. Scientific Reports 6 31794. (https://doi.org/10.1038/srep31794)

Rejraji H, Sion B, Prensier G, Carreras M, Motta C, Frenoux JM, Vericel E, Grizard G, Vernet P \& Drevet JR 2006 Lipid remodeling of murine epididymosomes and spermatozoa during epididymal maturation. Biology of Reproduction 74 1104-1113. (https://doi.org/10.1095/ biolreprod.105.049304)

Rodgers AB, Morgan CP, Bronson SL, Revello S \& Bale TL 2013 Paternal stress exposure alters sperm microRNA content and reprograms offspring HPA stress axis regulation. Journal of Neuroscience 33 9003-9012. (https://doi.org/10.1523/JNEUROSCI.0914-13.2013)

Rodgers AB, Morgan CP, Leu NA \& Bale TL 2015 Transgenerational epigenetic programming via sperm microRNA recapitulates effects of paternal stress. PNAS 112 13699-13704. (https://doi.org/10.1073/ pnas.1508347112)

Rompala GR, Finegersh A \& Homanics GE 2016 Paternal preconception ethanol exposure blunts hypothalamic-pituitary-adrenal axis responsivity and stress-induced excessive fluid intake in male mice. Alcohol 53 19-25. (https://doi.org/10.1016/j.alcohol.2016.03.006)

Rompala GR, Mounier A, Wolfe CM, Lin Q, Lefterov I \& Homanics GE 2018 Heavy chronic intermittent ethanol exposure alters small noncoding RNAs in mouse sperm and epididymosomes. Frontiers in Genetics 9 32. (https://doi.org/10.3389/fgene.2018.00032)

Rowlison T, Ottinger MA \& Comizzoli P 2018 Key factors enhancing sperm fertilizing ability are transferred from the epididymis to the spermatozoa via epididymosomes in the domestic cat model. Journal of Assisted Reproduction and Genetics 35 221-228. (https://doi.org/10.1007/ s10815-017-1083-3)

Saavedra-Rodriguez L \& Feig LA 2013 Chronic social instability induces anxiety and defective social interactions across generations. Biological Psychiatry 73 44-53. (https://doi.org/10.1016/j.biopsych.2012.06.035)

Salas-Huetos A, Blanco J, Vidal F, Grossmann M, Pons MC, Garrido N \& Anton E 2016 Spermatozoa from normozoospermic fertile and infertile individuals convey a distinct miRNA cargo. Andrology 4 1028-1036. (https://doi.org/10.1111/andr.12276)

Schuster A, Skinner MK \& Yan W 2016a Ancestral vinclozolin exposure alters the epigenetic transgenerational inheritance of sperm small noncoding RNAs. Environmental Epigenetics 2 dvw001. (https://doi. org/10.1093/eep/dvw001)

Schuster A, Tang C, Xie Y, Ortogero N, Yuan S \& Yan W 2016b SpermBase: a database for sperm-borne RNA contents. Biology of Reproduction 95 99. (https://doi.org/10.1095/biolreprod.116.142190) 
Schwarz A, Wennemuth G, Post H, Brandenburger T, Aumuller G \& Wilhelm B 2013 Vesicular transfer of membrane components to bovine epididymal spermatozoa. Cell and Tissue Research 353 549-561. (https://doi.org/10.1007/s00441-013-1633-7)

Sharma U, Conine CC, Shea JM, Boskovic A, Derr AG, Bing XY, Belleannee C, Kucukural A, Serra RW, Sun F et al. 2016 Biogenesis and function of tRNA fragments during sperm maturation and fertilization in mammals. Science 351 391-396. (https://doi.org/10.1126/science.aad6780)

Sharma U, Sun F, Conine CC, Reichholf B, Kukreja S, Herzog VA, Ameres SL \& Rando OJ 2018 Small RNAs are trafficked from the epididymis to developing mammalian sperm. Developmental Cell $\mathbf{4 6}$ 481-494.e6. (https://doi.org/10.1016/j.devcel.2018.06.023)

Short AK, Fennell KA, Perreau VM, Fox A, O'Bryan MK, Kim JH, Bredy TW, Pang TY \& Hannan AJ 2016 Elevated paternal glucocorticoid exposure alters the small noncoding RNA profile in sperm and modifies anxiety and depressive phenotypes in the offspring. Translational Psychiatry 6 e837. (https://doi.org/10.1038/tp.2016.109)

Short AK, Yeshurun S, Powell R, Perreau VM, Fox A, Kim JH, Pang TY \& Hannan AJ 2017 Exercise alters mouse sperm small noncoding RNAs and induces a transgenerational modification of male offspring conditioned fear and anxiety. Translational Psychiatry 7 e1114. (https:// doi.org/10.1038/tp.2017.82)

Song MS \& Rossi JJ 2017 Molecular mechanisms of Dicer: endonuclease and enzymatic activity. Biochemical Journal 474 1603-1618. (https:// doi.org/10.1042/BCJ20160759)

Song R, Hennig GW, Wu Q, Jose C, Zheng H \& Yan W 2011 Male germ cells express abundant endogenous siRNAs. PNAS 108 13159-13164. (https://doi.org/10.1073/pnas.1108567108)

Steger K 1999 Transcriptional and translational regulation of gene expression in haploid spermatids. Anatomy and Embryology 199 471-487. (https://doi.org/10.1007/s004290050245)

Suganuma R, Yanagimachi R \& Meistrich ML 2005 Decline in fertility of mouse sperm with abnormal chromatin during epididymal passage as revealed by ICSI. Human Reproduction 20 3101-3108. (https://doi. org/10.1093/humrep/dei169)

Sullivan R 2015 Epididymosomes: a heterogeneous population of microvesicles with multiple functions in sperm maturation and storage. Asian Journal of Andrology 17 726-729. (https://doi.org/10.4103/1008-682X.155255)

Sullivan R \& Saez F 2013 Epididymosomes, prostasomes, and liposomes: their roles in mammalian male reproductive physiology. Reproduction 146 R21-R35. (https://doi.org/10.1530/REP-13-0058)

Sutherland JM, Siddall NA, Hime GR \& McLaughlin EA 2015 RNA binding proteins in spermatogenesis: an in depth focus on the Musashi family. Asian Journal of Andrology 17 529-536. (https://doi.org/10.4103/1008682X.151397)

Thimon V, Frenette G, Saez F, Thabet M \& Sullivan R 2008 Protein composition of human epididymosomes collected during surgical vasectomy reversal: a proteomic and genomic approach. Human Reproduction 23 1698-1707. (https://doi.org/10.1093/humrep/den181)
Thomson T \& Lin H 2009 The biogenesis and function piwi proteins and piRNAs: progress and prospect. Annual Review of Cell and Developmental Biology 25 355-376. (https://doi.org/10.1146/annurev. cellbio.24.110707.175327)

Verdel A, Vavasseur A, Le Gorrec M \& Touat-Todeschini L 2009 Common themes in siRNA-mediated epigenetic silencing pathways. International Journal of Developmental Biology 53 245-257. (https://doi.org/10.1387/ ijdb.082691av)

Wang K, Zhang S, Weber J, Baxter D \& Galas DJ 2010 Export of microRNAs and microRNA-protective protein by mammalian cells. Nucleic Acids Research 38 7248-7259. (https://doi.org/10.1093/nar/gkq601)

Wang Y, Liu H \& Sun Z 2017 Lamarck rises from his grave: parental environment-induced epigenetic inheritance in model organisms and humans. Biological Reviews of the Cambridge Philosophical Society 92 2084-2111. (https://doi.org/10.1111/brv.12322)

Weissman A, Horowitz E, Ravhon A, Nahum H, Golan A \& Levran D 2008 Pregnancies and live births following ICSI with testicular spermatozoa after repeated implantation failure using ejaculated spermatozoa. Reproductive Biomedicine Online 17 605-609. (https://doi.org/10.1016/ S1472-6483(10)60306-9)

Yanagimachi R, Kamiguchi Y, Mikamo K, Suzuki F \& Yanagimachi H 1985 Maturation of spermatozoa in the epididymis of the Chinese hamster. American Journal of Anatomy 172 317-330. (https://doi.org/10.1002/ aja.1001720406)

Yi R, Qin Y, Macara IG \& Cullen BR 2003 Exportin-5 mediates the nuclear export of pre-microRNAs and short hairpin RNAs. Genes and Development 17 3011-3016. (https://doi.org/10.1101/gad.1158803)

Yuan S, Tang C, Zhang Y, Wu J, Bao J, Zheng H, Xu C \& Yan W 2015 mir$34 \mathrm{~b} / \mathrm{c}$ and mir-449a/b/c are required for spermatogenesis, but not for the first cleavage division in mice. Biology Open 4 212-223. (https://doi. org/10.1242/bio.201410959)

Yuan S, Schuster A, Tang C, Yu T, Ortogero N, Bao J, Zheng H \& Yan W 2016 Sperm-borne miRNAs and endo-siRNAs are important for fertilization and preimplantation embryonic development. Development 143 635-647. (https://doi.org/10.1242/dev.131755)

Zhou W, De Iuliis GN, Dun MD \& Nixon B 2018 Characteristics of the epididymal luminal environment responsible for sperm maturation and storage. Frontiers in Endocrinology 9 59-59. (https://doi.org/10.3389/ fendo.2018.00059)

Received 11 September 2018

First decision 16 October 2018

Revised manuscript received 30 January 2019

Accepted 18 February 2019 